\title{
Shotgun Analysis of Integral Membrane Proteins Facilitated by Elevated Temperature
}

\author{
Anna E. Speers, Adele R. Blackler, and Christine C. Wu \\ Department of Pharmacology, University of Colorado School of Medicine, Aurora, \\ CO, 80045

\section{Supporting Information}

In this document:

Figure S1. Column heater illustration

Figure S2. Graph of protein identifications vs. temperature showing column degradation above $60{ }^{\circ} \mathrm{C}$

Separate Files:

Table S1. Proteins \& peptides identified in trypsin digest samples (PDF)

Table S2. TMD peptides identified in trypsin digest samples (PDF)

Table S3. Proteins \& peptides identified in MEP samples (PDF)

Table S4. MEP retention times and TMD overlap (PDF)

Combined Tables S1-4 (Excel) 


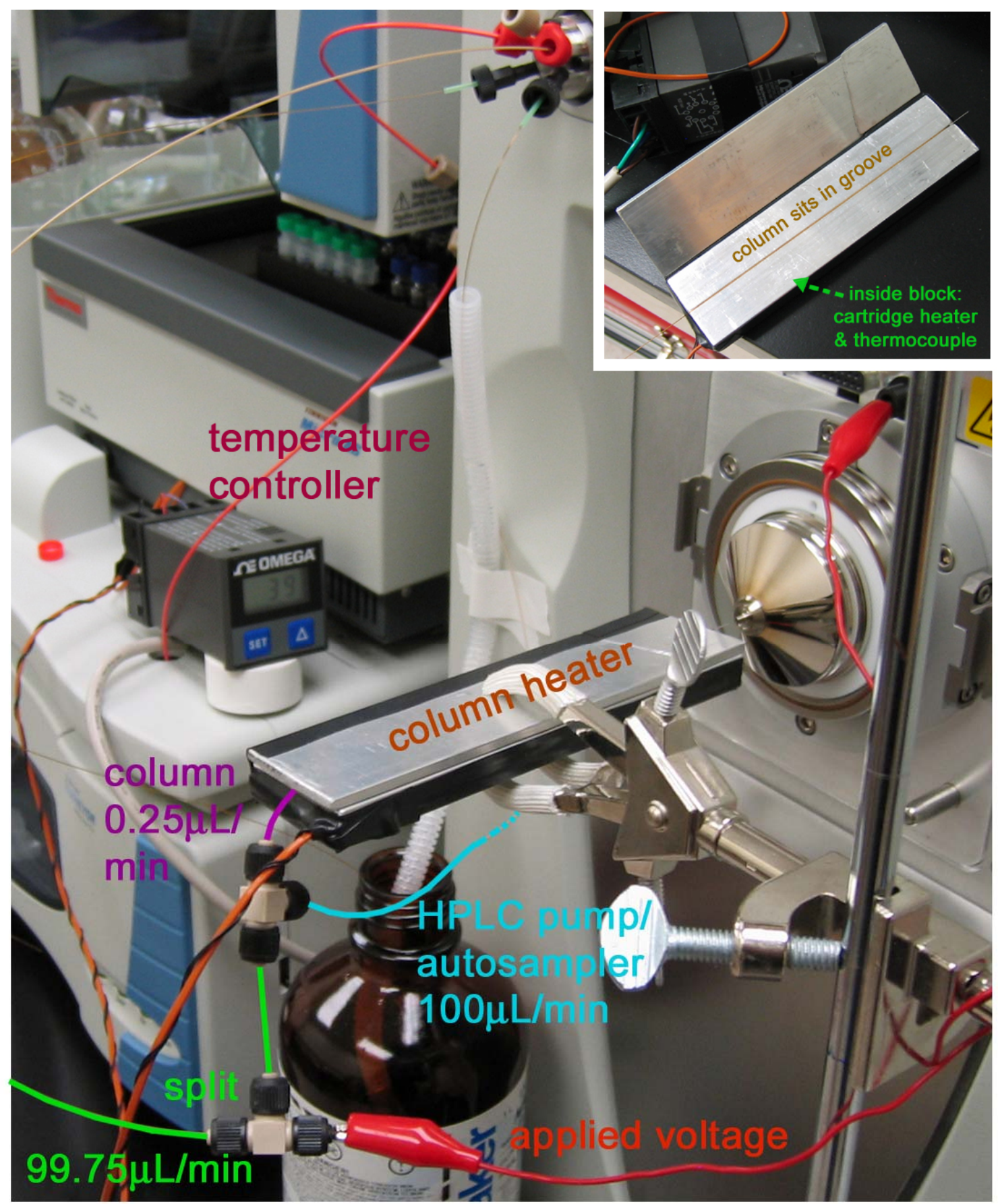

Figure S1. Illustration of column heater setup for $\mu \mathrm{LC}-\mathrm{MS} / \mathrm{MS}$. Inset: open column heater. 
Trypsin Digest: Protein Identifications as a function of Temperature

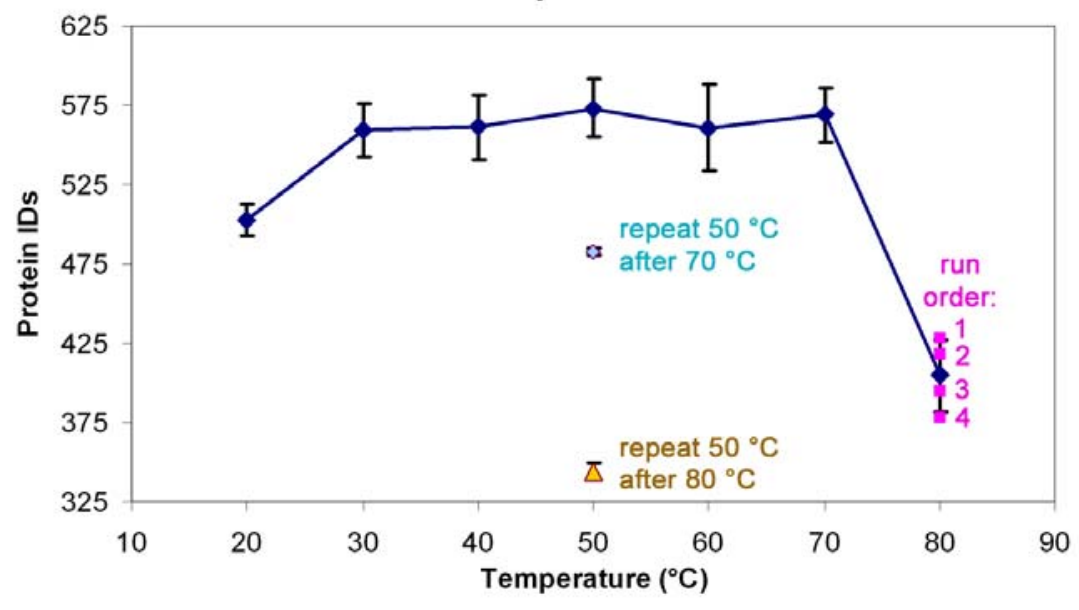

Figure S2. Protein identifications vs. temperature for trypsin digest runs (Data set collected prior to that presented in paper). $\mathrm{n}=3$ or 4 for each point. Note: repeating runs at lower temperature after running at $60^{\circ} \mathrm{C}$ does not result in decreased protein identifications (unpublished results). 